\title{
Establishment of digital 3D map based on discrete elevation point data measured in the field
}

\author{
Aimin Li ${ }^{1,2,3}$, Zhiwen Han ${ }^{1, *}$, Caiyun Guo ${ }^{3,4}$ and Shuai Zhong ${ }^{1,3}$ \\ ${ }^{1}$ Key Laboratory of Desert and Desertification, Northwest Institute of Eco-Environment and Resources, \\ Chinese Academy of Sciences, Lanzhou 730 000, China. \\ ${ }^{2}$ College of Urban Construction, Heze University, Heze 274015 , China. \\ ${ }^{3}$ University of Chinese Academy of Sciences, No. 19A, Yuquan Road, Shijingshan District, \\ Beijing 100 049, China. \\ ${ }^{4}$ Key Laboratory of Land Surface Pattern and Simulation, Institute of Geographic Sciences and \\ Natural Resources Research, Chinese Academy of Sciences, Beijing 100 101, China. \\ *Corresponding author.e-mail: hzwen@lzb.ac.cn
}

MS received 27 February 2017; revised 13 February 2018; accepted 26 April 2018; published online 19 January 2019

This study established a survey zone digital elevation model (DEM) using highly precise and regularly updated three-dimensional coordinates of the surface of barchan dunes using CASS9.0 software. Two contour plots were drawn, one for the entire survey zone drawn with a contour interval of $0.005 \mathrm{~m}$ and one for an individual sand dune drawn with a contour interval of $0.001 \mathrm{~m}$. ArcMap10 was used to define the projection of the created contour lines in DWG format and export the data into shape files to enable the creation of a triangulated irregular network (TIN). Next, TIN data was converted into raster data to facilitate our analysis and data processing. We created the final TIN by using an additional smoothing processing on the desired area that had been clipped out. We added the TIN data to the ArcScene module to establish the final 3D numerical model of barchan dunes. This model extracts and analyzes the changes in the characteristic parameters of the barchan dune as its topography changes in real time so researchers can visualize dune migration and evolution. Their understanding is enhanced by comparing and superposing the various $3 \mathrm{D}$ dune models on different days.

Keywords. Barchan dune; DEM; TIN; 3D simulation.

\section{Introduction}

Barchan dunes are widely distributed in deserts all over the world, thus making their formation, development and evolution a series of hot topics among researchers who study aeolian sand landforms and blown sand physics (Abolkhair 1986; Wu 1987; Käln and Adelaide 1988; Endo et al. 2004; Hugenholtz and Wolfe 2005; Dong et al. 2009; Durán et al. 2009; Gómez-Ortiz et al. 2009; Tsoar and Parteli 2016). As mobile entities, barchan dunes often indicate the material transportation direction on earth's surface with the direction of its own movement. Further, a dune's moving velocity can be used to estimate the quantity of sand sediment. The metrics of barchan dunes have become important reference indexes in wind and sand fixation engineering (Mckee 1966; Wu 1987; Frank and Kocurek 1996; Stam 1997; Parsons et al. 2004b; Kocurek and Ewing 2005; Dinieg et al. 2010; Faria et al. 2011; Palmer et al. 2012). Although significant progress has been made in the research 




Figure 1. The location of barchan dune survey zone.

of dune development modes and conditions, their morphological evolution, the surface air flow and eroded sedimentation, the wind-sand flow structure and sediment transport rate, the sedimentary structure and the dune moving laws, there is still no consensus on the process of morphological evolution of dunes, the velocity and direction of moving dunes and what its influential factors are (Weng et al. 1991; Wiggs et al. 1996; Zhang et al. 1999; Walker and Nickling 2003; Elbelrhiti et al. 2005; Baddock et al. 2007; Li et al. 2007; Samani et al. 2016). Through measuring 3D coordinates of several dunes with high-precision, this study establishes a digital elevation model (DEM) that can be used for a 3D simulation of dune migration. This model can recreate single-period or multi-period scenarios.

\section{Selection of survey zone and data acquisition}

\subsection{Selection of survey zone}

Between the complex and longitudinal dunes to east $\left(39^{\circ} 15^{\prime} \mathrm{N}, 83^{\circ} 42^{\prime} \mathrm{E}\right)$ of Tazhong Union Station in the Taklimakan desert hinterland area lies this study's focal barchan dune development and evolution survey zone. Within the $6700 \mathrm{~m}^{2}$ zone, tools were set up to make regular measurements of the $3 \mathrm{D}$ coordinates of the surface of the sand dune (figure 1).

The research area has a typical temperate continental climate, with an annual precipitation of less than $50 \mathrm{~mm}$ and an annual evaporation greater than $3000 \mathrm{~mm}$. The mean relative humidity in July is $35 \%$ and the minimum relative humidity can be as low as $0 \%$. It is extremely hot in the summer, but rather cold in winter, with a maximum annual temperature difference as high as $70^{\circ} \mathrm{C}$. The site may be windy for up to 7 months each year, with a dominant northeasterly wind and a maximum wind speed of $30 \mathrm{~ms}^{-1}$ (Li and Chen 1999; Han et al. 2012). In the area, low lands alternate with complex and longitudinal dunes, where the longitudinal dunes face $\mathrm{N} 56^{\circ} \mathrm{E}-\mathrm{N} 50^{\circ} \mathrm{E}$ with an altitude of $60-80$ $\mathrm{m}$ and the main dune stretches abnormally with an asymmetrical transect. The northwest (NW) slope, which is also the slip face, has an altitude of 30$60 \mathrm{~m}$ and a gradient around $32^{\circ}$. The southeast (SE) side has a gentler slope and is overlain by a barchan dune and located on a secondary ridge, or a sparse barchan array, heading in the same direction of the sand ridge. A few isolated barchan dunes stand at 1-2 $\mathrm{m}$ in the 1-2 $\mathrm{km}$ wide stretch of low land between the sand ridges, where the slip face 

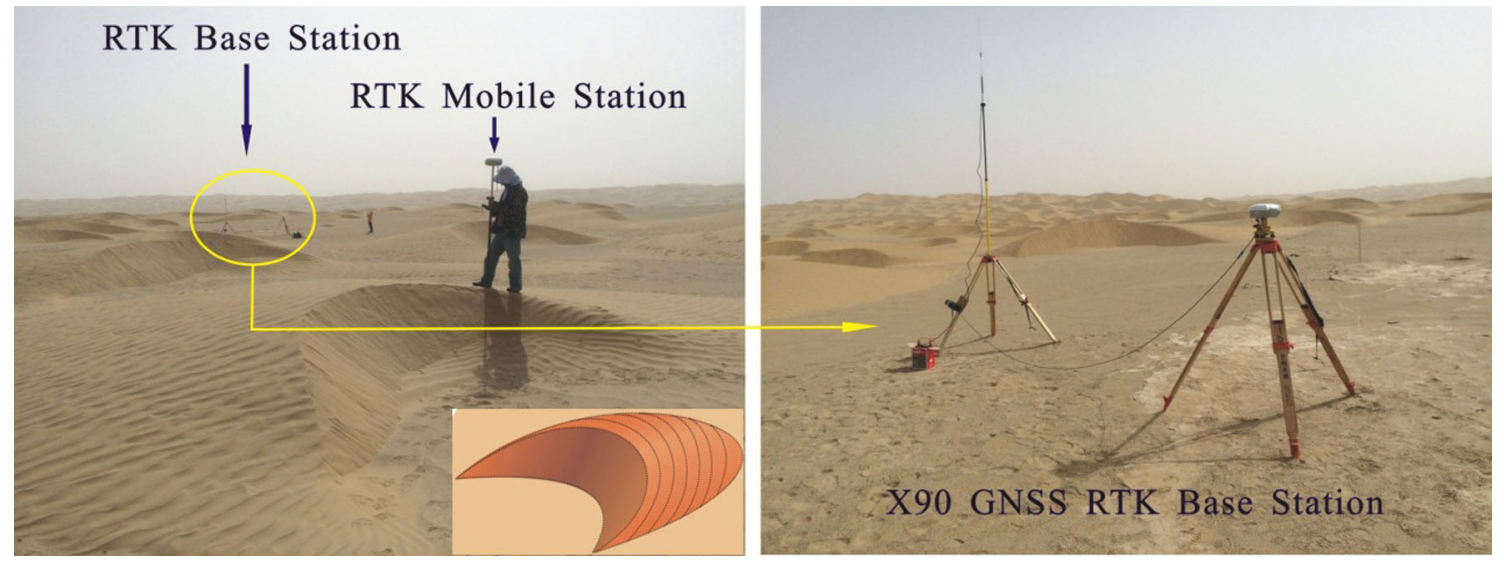

Figure 2. The measurement of discrete elevation point data.

has an angle around $32^{\circ}$ on a trend of $\mathrm{S} 70^{\circ} \mathrm{W}$. The gradient of the windward slope is around $11^{\circ}$. The above description is characteristic of a typical dune development zone (Wu 1987; Han et al. 2012).

\subsection{Acquisition of dune coordinates}

The 3D coordinate in the barchan dune evolution monitoring zone were measured with the application of Huace X90 GNSS receiver, which consists of base station, mobile station, data chain and control software (figure 2). The base station sends the differential correction data through data links via a radio station to the mobile station, where data is resolved immediately after it is received for the acquisition of high-precision spatial data about the position of the mobile station ( $\mathrm{Li} 2010$ ).

An RTK (Real Time Kinematic) operation mode was chosen for the measurements taken by the X90 GNSS receiver. The RTK positioning technology provided 3D coordinates of the location of the station in real time on an appointed coordinate system at millimeter-level precision ( $\mathrm{Li} 2010$; Tang et al. 2010). The base station from which the measurements were made was configured before starting to collect the site measurements of the translational movement of the base station.

The sand dune measurement path was set approximately, according to the contour lines. Two measuring points were set about $0.5 \mathrm{~m}$ from each other on the same path (figure 2). Expanding this idea to the entire survey area, the measuring points were distributed on a grid covering the sand dune surface with a spatial resolution of $50 \times 50 \mathrm{~cm}$. The density of the measuring points increased in areas where the terrain changes. Throughout the whole measuring process, point A (figure 1) was used as the datum point and point B (figure 1) as the point to test the accuracy in measuring the shifting base station.

Because of the substantial weight of digital field books and measuring rods, it is difficult to prevent the rod from sinking into the sand surface. At the same time, the tread of surveyors can cause slight damage to the dune's natural surface. Added weight and influence on the dune can alter measurements and reduce accuracy. To minimize measurement error, a circular rubber pad with a diameter of $5 \mathrm{~cm}$ and a thickness of $0.5 \mathrm{~cm}$ was fixed at the bottom of the measuring rod to prevent it from sinking further into the dune. In addition, the rod was placed as far as possible from the surveyor trails to avoid disturbance from surveyor steps.

\section{3D numerical sand dune simulation technology}

A typical barchan survey zone was built in the Taklimakan desert hinterland area. Using a Huace X90 GNSS receiver to obtain detailed measurements of 3D terrain coordinates, our team obtained the 3D coordinates of the dune surface with millimeter precision. Based on this survey zone, the DEM was established using CASS9.0 software, as well as ArcGIS10 to process the relevant spatial data and build the 3D simulation of barchan dunes (Ling et al. 1998; Huang et al. 2007; Du et al. 2011; Cong et al. 2014). Our study will continue to collect data, even as we analyze, which will make it possible to study the barchan dune evolution process and to interpret the dune evolution mechanism 
both today and in the future (Katsuki et al. 2004; Bo and Zheng 2011).

\subsection{The establishment of sand dune DEM and the generation of contour lines}

A digital terrain model (DTM) highlights distinctive topographic features along a coordinate system of regularly spaced points. The DTMs also provide digital description of a terrain with its spatial position character and terrain attributive character (Tang et al. 2010; Yang et al. 2016). Here, $x$ and $y$ represent the longitudinal and latitudinal coordinates of the point, respectively, and $z$ might indicate the elevation, gradient or slope information. When $z$ represents elevation, the model is best described as a digital elevation model (DEM). A subset of DTM, DEM is a data set of ground and elevation information described with regular grid points within a certain range. Because ground elevation reflects the spatial distribution of topographic features, elevation constitutes the most important basis for topographic data and geoanalysis. Currently, elevation is also one of the most effective metrics to acquire ground surface information (Tang et al. 2010; Samavati and Runions 2016).

To make this model, the measured 3D coordinates that were collected in the field were first exported as 'DAT' files and read by the CASS9.0 software. In the software, the elevation points were plotted at an interval of $0.1 \mathrm{~m}$. Next, the program plotted the boundary line of the survey zone by using polyline (PL) and ran the close command to enclose the boundary line of the survey zone. The DTM was then generated with the elevation data by using the 'Create DTM' command on the 'Contour Line' menu bar (figure 3).

After the establishment of a survey zone DEM, the next step was to create the contour lines for the model. First, 'Plot contour line' under the 'Contour line' menu bar was used to plot the contour lines with an interval of $0.005 \mathrm{~m}$ for the whole survey zone, and with an interval of $0.001 \mathrm{~m}$ for an individual sand dune. The smaller the contour interval was set, the smoother the established 3D model would be. Because model takes longer to load at a smaller contour interval, it is necessary to set a proper contour interval value that will not lead to impractically slow models. In normal cases, contour lines are plotted in the following two methods: the cubic B spline approximation and the spline fitting method. In cubic B spline approximation, the

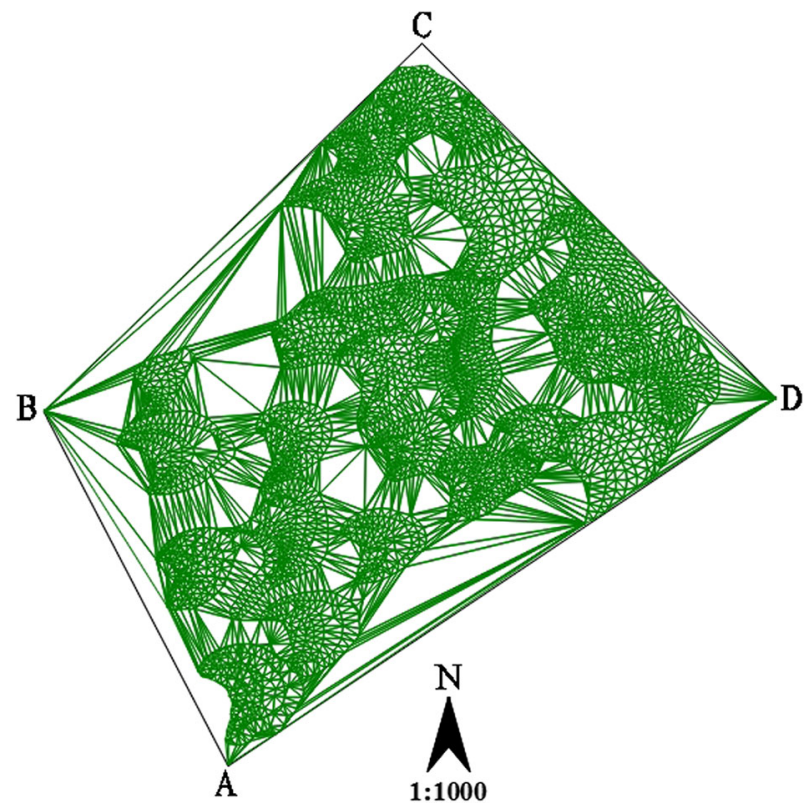

Figure 3. The DEM of the whole survey zone.

modeling speed slows due to the large data size of the contour line that has been created. The large amount of data is a result of many additional grips and the failure in generating a spline curve after the clipping, but the contour line created is very clear, which can prevent the occurrence of spline intersection. As for the spline fitting method, the plotted contour lines are suitable for further editing after the clipping, but the lines are rather unclear, which makes them liable to spline intersection. Weighing the costs and benefits, the 'cubic B spline approximation' method was adopted to create the contour lines for the whole survey zone and the individual sand dune (figure 4).

\subsection{Define projection}

The natural surface of the earth cannot be used as the datum plane for measurement and mapping because it cannot be expressed by a mathematical formula, due to its uneven and irregular nature $(\mathrm{Li}$ 2010; Mou et al. 2012). Due to this limitation, projections are used as a medium to model the earth's surface. In this study, the Beijing 54 coordinate system was chosen to replace the natural surface of the earth for measurement and plotting purposes.

The Beijing 54 coordinate system is the basic system for geodetic measurement. Although the surface of the earth is an undevelopable surface, the position of any point on the spheroid can be indicated by a longitude and latitude in a geographic coordinate system. On the other hand, when 


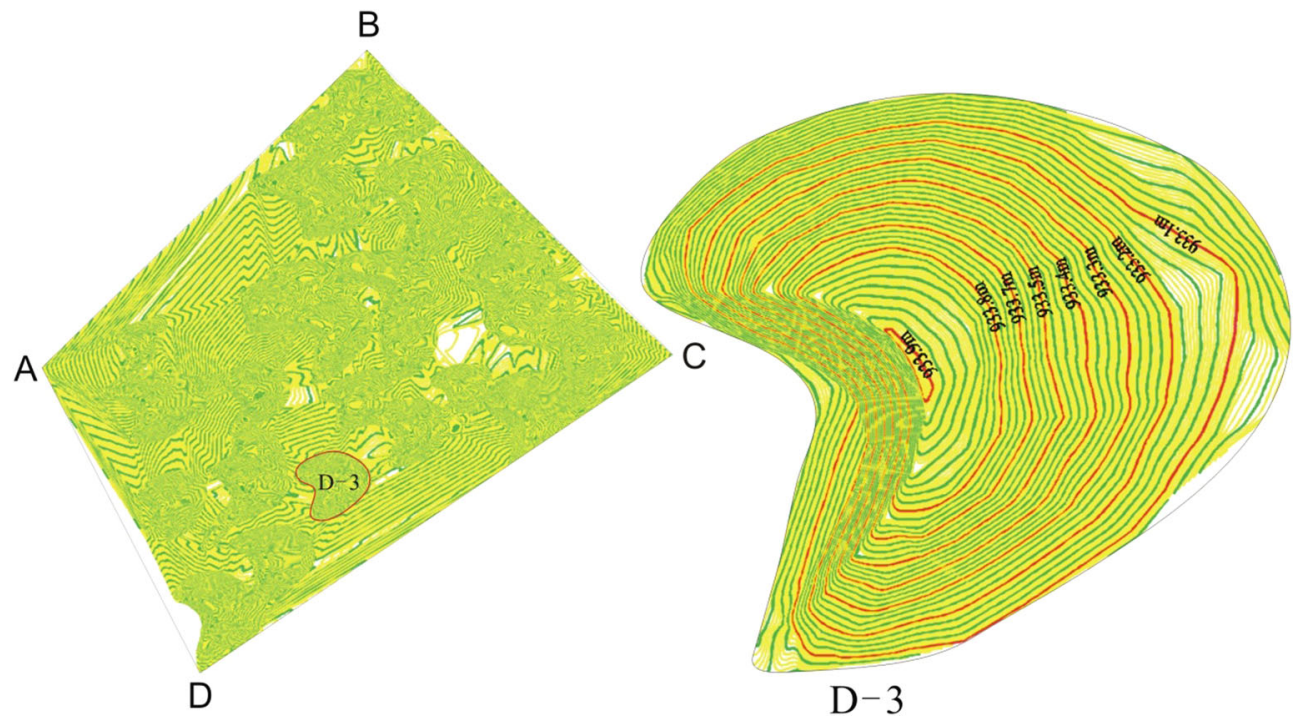

Figure 4. The contour lines with an interval of $0.005 \mathrm{~m}$ for the whole survey zone.

dealing with planar surfaces, points are always indicated by either rectangular coordinates $(x, y)$ or polar coordinates $(\gamma, \theta)$. An additional conversion factor, known as a map projection, helps establish the functional relationship between a point on a plane to a point on a sphere (Mou et al. 2012; Moosavi et al. 2014). The map projection scheme in China stipulates that all topographic maps with scales greater than 1:10000 must be made based on the Gauss-Kruger projection of $3^{\circ}$ zone. Therefore, the Gauss-Kruger projection of $3^{\circ}$ zone was also adopted in this study.

The Gauss-Kruger projection assumes the transverse tangent of an elliptic cylinder surface that relates to the ellipsoidal surface of the earth on a certain longitude. The projection of longitudinal lines lie east and west of the central meridian line within the longitudinal extent of $3^{\circ}$ or $1.5^{\circ}$ onto the elliptical cylindrical surface according to the conformal conditions. Finally, the elliptical cylindrical surface unfolds into a plane (Li 2010; Qi et al. 2014). Through this projection method, there is neither angular deformation nor length deformation along the central meridian line. The longitudes show a positive length deformation, which increases in deformation with the increase in distance away from the central meridian line. To control and reduce the projection deformation, the $6^{\circ}$ and $3^{\circ}$ zoning methods were applied to the GaussKruger projection. This zonal division results in less projection deformation. The Tazhong survey zone $\left(83^{\circ} 42^{\prime} \mathrm{E}\right)$ is located in the twenty-eighth division zone $\left(82^{\circ} 30^{\prime}-83^{\circ} 42^{\prime} \mathrm{E}\right)$ through the $3^{\circ}$ zoning method.
ArcToolbox in ArcMap10 was used to define the projection of the contour lines with established intervals of 0.005 and $0.001 \mathrm{~m}$ from on the CASS9.0 software. We followed the commands: 'Data Management Tools $\rightarrow$ Projections and Transformation $\rightarrow$ Define Projection'. The survey zone in this study was in zone 28 within the Beijing 54 coordinate system and the $3^{\circ}$ zoning method in the Gauss-Kruger projection. In conclusion, the specific parameters used to define the projection can be recreated with the following route: 'Projected Coordinate Systems $\rightarrow$ Gauss-Kruger $\rightarrow$ Beijing $1954 \rightarrow$ Beijing 19543 Degree GK Zone 28.prj'.

\subsection{Establishment of $3 D$ sand dune model}

Both ArcMap10 and ArcScene10 in ArcGIS desktop, which were developed by Esri, were used to model the $3 \mathrm{D}$ simulation of sand dunes in this study. A popular tool, ArcMap10 provided all the map-based functions, including map making, map editing and map analysis. ArcScene10 is more of a $3 \mathrm{D}$ visual application program and supported the 3D analysis through the creation, display and analysis of TIN (Tang and Yang 2012; Xia and Dong 2016).

Figure 5 shows the technical routes for the 3D simulation of a single sand dune studied in this paper. The $3 \mathrm{D}$ simulation of the whole survey zone is similar to the case of a single sand dune. The only difference lies in the grid-based clipping, which is not required in the simulation of the whole survey zone. 


\subsubsection{Creation of a raster file}

The 'Add data' command was selected in ArcMap to add the 'Contour line.dwg' file that had been defined so that the CAD projection could be incorporated into the software. CAD data can only be read and not edited in ArcMap, so the CAD data was exported into a shapefile (.shp) before the triangulated irregular network (TIN) could be established. Next, the polyline features

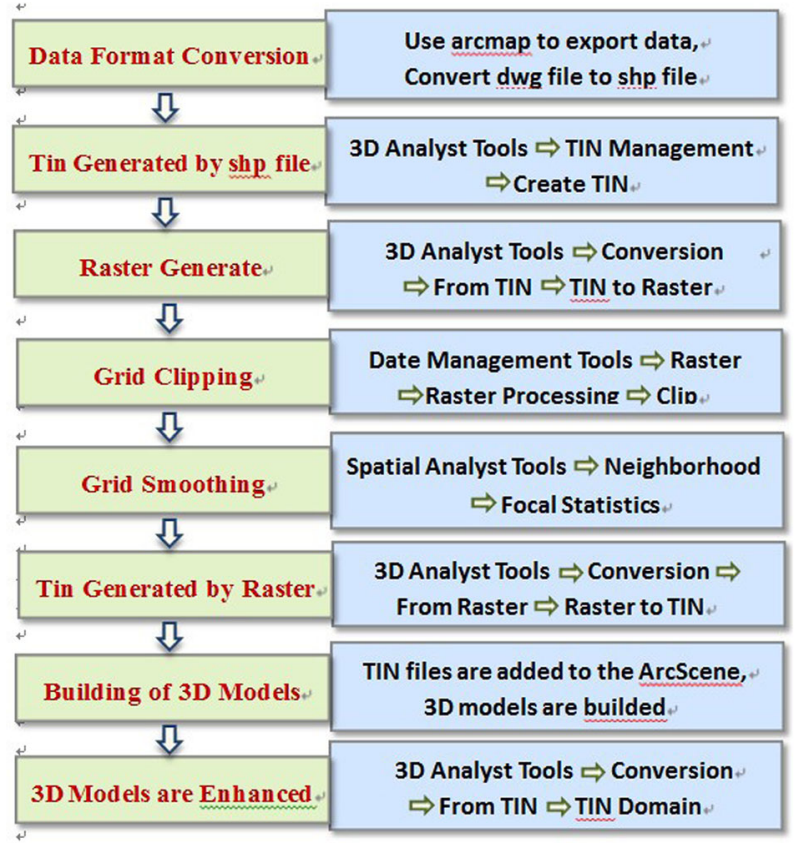

Figure 5. Technical routes for the digital 3D map simulation of a single barchan dune. were exported from the 'Contour line.dwg' layer group into a .shp format as well, following the technical route: 'Data $\rightarrow$ Export Data $\rightarrow$ the data frame'. Shapefiles are vector data files developed by Esri to maintain geometric properties and attribute information of spatial data when transferring it to another application (Tang et al. 2010). Choosing 'data frame' to export data will ensure that the entire data frame uses the same coordinate system.

Triangulated irregular network was established based on the shapefile created above and is composed of a series of nodes with $X, Y$ and $Z$ values. Based on the vector digital geographic data, it indicates the surface morphology in digital form as an approach to express DEM (Yan and Yang 2009; Wang et al. 2015). In a TIN, the density and position of the sampling points is determined by the slope of the terrain to avoid data redundancy when a terrain is flat. Additionally, a TIN highlights areas of topographic diversity and interest, such as ridges, valley lines and terrain variation lines. TIN has been used frequently in the high-precision modeling of small regions (Xiang et al. 2009; Tang and Yang 2012). The TIN can be generated from the shapefile by clicking through the following options in ArcToolbox of ArcMap10: '3D Analyst Tools $\rightarrow$ TIN Management $\rightarrow$ Create TIN' (figure 6).

The TIN data was then transformed into raster data. The raster format reflects detailed changes in elevation and better facilitates further analysis and processing with simple topological relations. Raster data takes the form of a Descartes matrix, where each grid cell has a unique row and column address and represents an equal-sized area (Chen

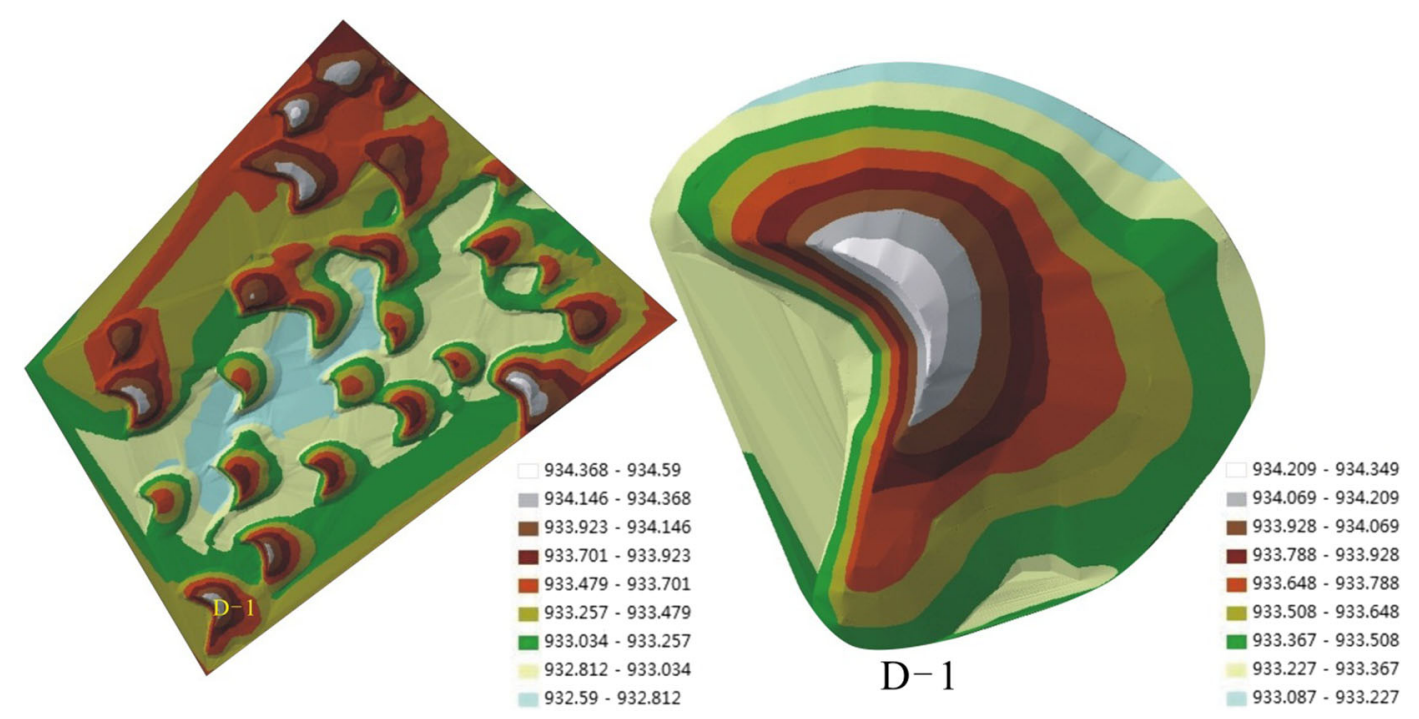

Figure 6. The TIN of the whole survey zone and a single barchan dune. 

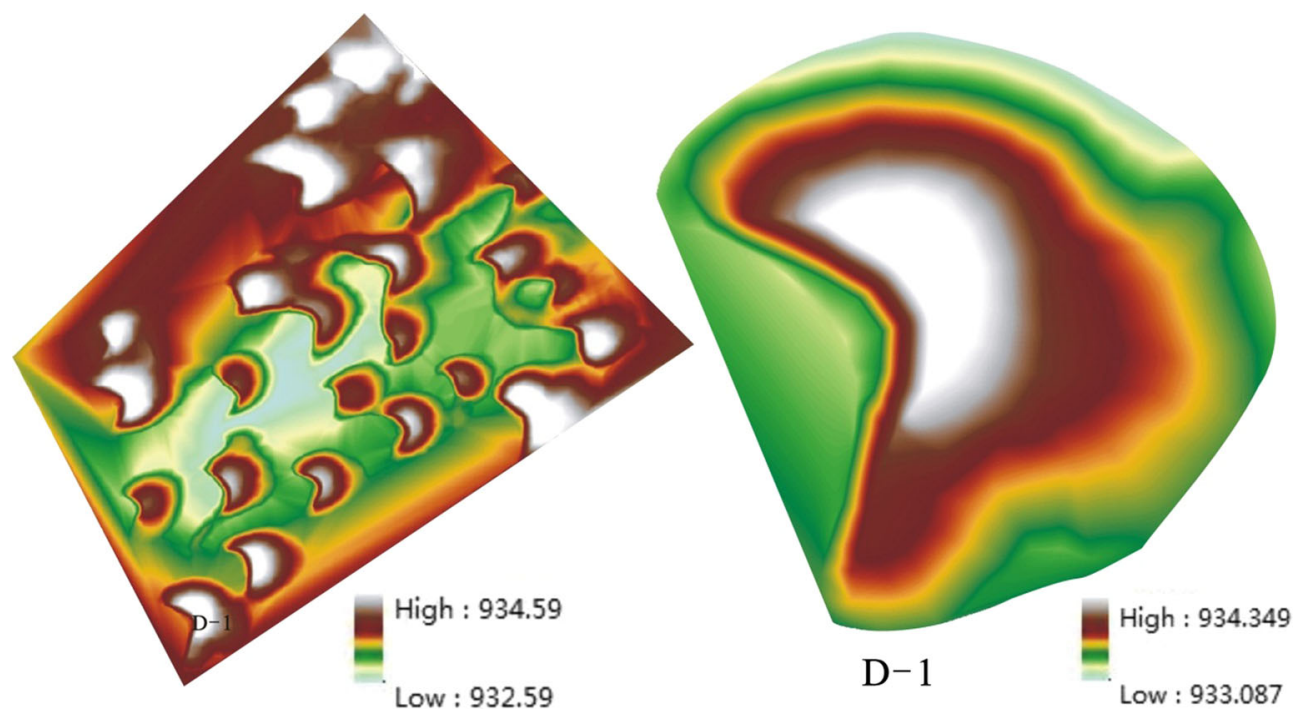

Figure 7 . The raster of the whole survey zone and a single barchan dune.

2005; Katagiri et al. 2010). A large cell size will lead to reduced accuracy of analysis, but a small cell size will give rise to redundant data and decrease computing speed (Ruiz-arias et al. 2009; Tang et al. 2010). However, selecting the most efficient cell size requires a comprehensive consideration of the following: spatial resolution of the input data, analysis software, the size of the resulting database and the time allotted for the study, etc.

The natural neighbor interpolation method was adopted to transform the TIN into raster data (Sibson 1981). This method is used to detect the input sample set that is nearest to the query point and proportionally interpolate the weight of these samples according to the region size. Compared with the linear interpolation method, this method results in smoother data. Float was chosen to save the altitude values in decimal format (Schwämmle and Herrmann 2005; Tang and Yang 2012). The raster cell size was then set at $0.01 \mathrm{~m}$ following a comprehensive consideration of the various factors mentioned in the previous paragraph. Selecting the following options in ArcToolbox in ArcMap10 will replicate the process by which we generated the raster image of a single sand dune and that of the larger survey zone, based on TIN data: '3D Analyst Tools $\rightarrow$ Conversion $\rightarrow$ From TIN $\rightarrow$ TIN to Raster' (figure 7).

\subsubsection{Processing of raster files}

Figure 7 reveals redundancy in the raster image of a single sand dune created with TIN data. Thus, it is necessary to zoom in on the desired region by clipping. Raster data can be clipped through multiple approaches based on circles, points, polygons, rectangles and the existing data. The most common method of clipping is by using existing grid or vector data (Mou et al. 2012). The following command line in ArcToolbox in ArcMap10 shows how we used the vector file in shapefile format for the boundary line of a single sand dune to clip the raster image of a single sand dune: 'Data Management Tools $\rightarrow$ Raster $\rightarrow$ Raster Processing $\rightarrow$ Clip' (figure 8 ). When setting up clipping parameters, be sure to select 'Apply inputted features to geometric clipping'. If this step is skipped, the clipping will go beyond the scope of the region enclosed by the boundary line of a single sand dune.

Inconformity, also called noise, is found between some individual raster cells and the surrounding cells (figure 9), which leads to an obscure image or unclear boundary and interferes with analysis. To prevent noise, the raster data underwent a smoothing process (Parsons et al. 2004a; Tang et al. 2010).

The focal statistics tool was used to smooth the raster data (Werner 1995; Tang and Yang 2012). The tool performs a neighborhood operation on each cell where the output value is a function of all initial cell values in the neighborhood specified around the cell of interest. The command flow that will replicate our method in ArcToolbox in ArcMap10 is as follows: 'Spatial Analyst Tools $\rightarrow$ Neighborhood $\rightarrow$ Focal Statistics' (figure 9). In the smoothing process, circle was chosen as the type for neighboring analysis with the radius set to be 0.1 m. The MEAN was chosen as the statistics type. 

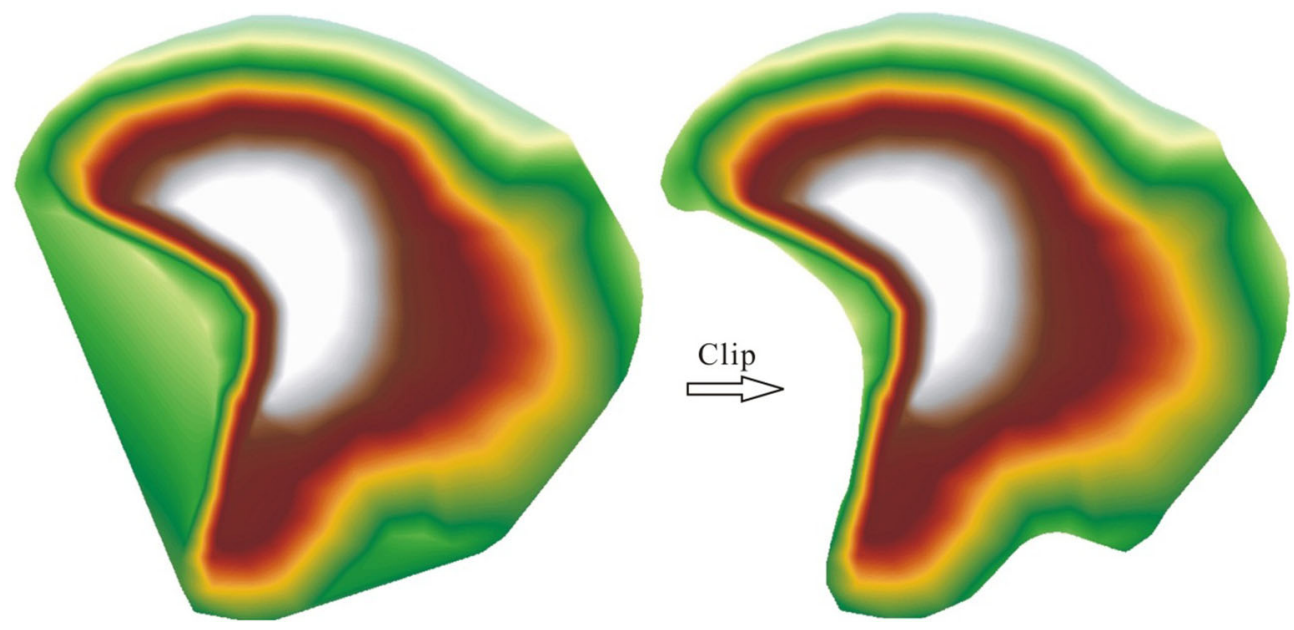

Figure 8. Raster clipping of a single barchan dune.
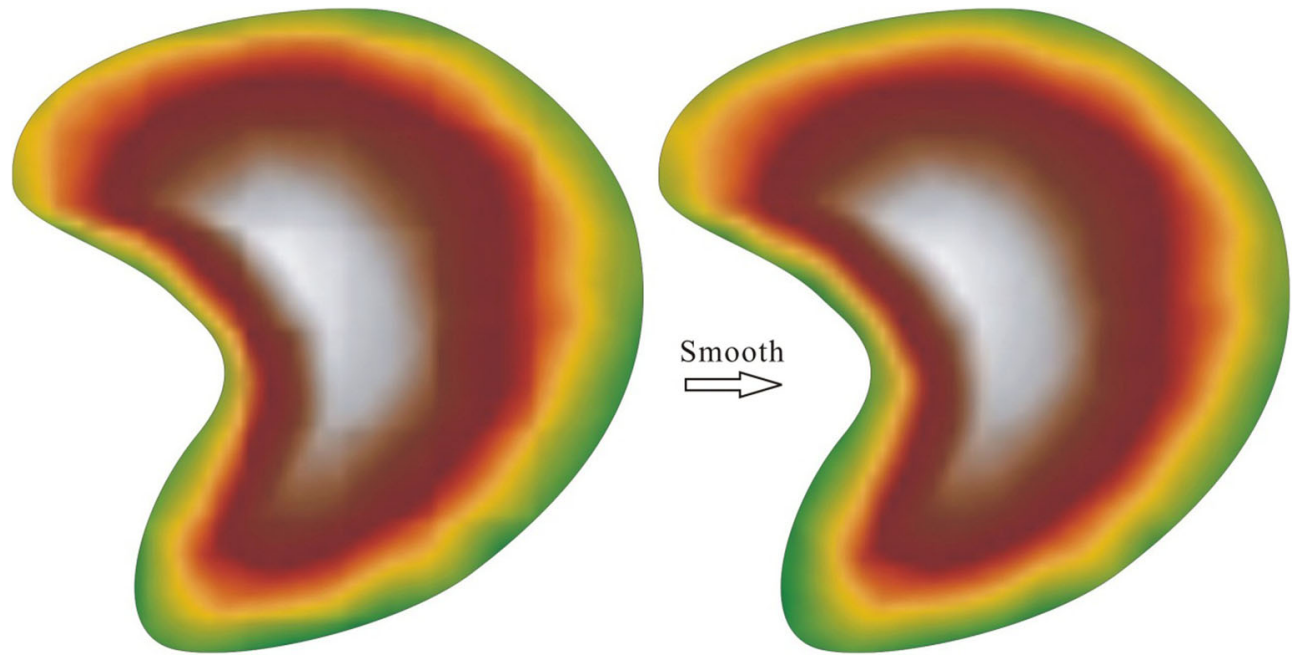

Figure 9. Raster smoothing of a single barchan dune.

\subsubsection{Generation of 3D model}

With all the previous data conversions in place, the final 3D model can be made. After clipping and smoothing the raster data, the following command flow in ArcToolbox in ArcMap10 was used to convert the raster data into the final TIN data: '3D Analyst Tools $\rightarrow$ Conversion $\rightarrow$ From Raster $\rightarrow$ Raster to TIN'. The TIN data was then added into the ArcScene10 module to establish a 3D sand dune surface model. As an open graphics librarybased 3D visual application program in ArcGIS, ArcScene10 supports the display of TIN data. The model shows the planar projection of the data on the spatial reference defined by the current scenario and reads all the data into the scenario for full display. Therefore, this model can be applied to the elaborate description of scenarios in small areas with small datasets, such as the region studied in this paper (Hersen 2004; Mou et al. 2012).

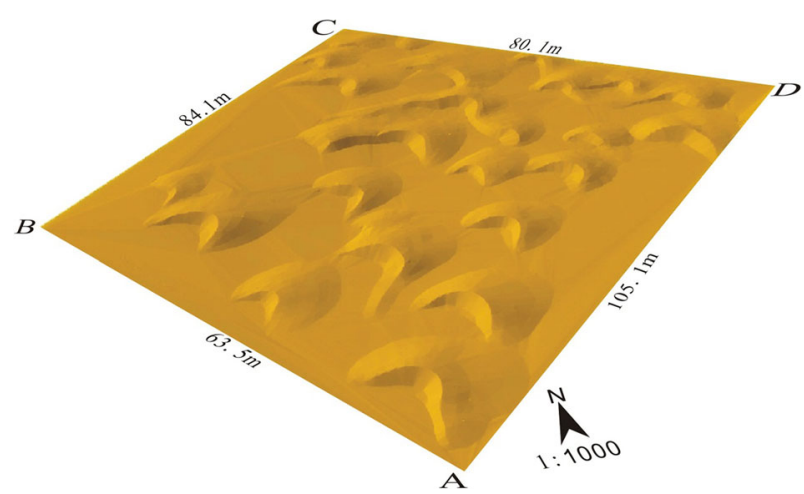

Figure 10. The digital 3D map of the whole survey zone.

After the TIN data was added into ArcScene10, the option 'Surface with the same symbols' was chosen in the symbol system of layer properties to display the $3 \mathrm{D}$ sand dune surface model. To augment the reality of the 3D model, the scope of TIN was further altered through the following 
command flow in ArcToolbox in ArcScene10: '3D Analyst Tools $\rightarrow$ Conversion $\rightarrow$ From TIN $\rightarrow$ TIN Domain'. Polygon was chosen as the output feature class type to generate the final 3D model of the sand dune (figure 10).

\section{Problem and discussion}

Using highly precise measurements, this study established contour lines at an interval of $0.005 \mathrm{~m}$ for the whole survey zone and at an interval of 0.001 $m$ for an individual sand dune on a DEM of the survey area. ArcMap10 was utilized for map making, map editing and analysis to further analyze the spatial data collected on the above described grid. Secondly, ArcScene10 was used to establish a 3D numerical model of the sand dune. Only one approach to establish the 3D model of a barchan dune was explored in this study, but through future model comparisons, we may find a simpler way to characterize a sand dune. Our model excels at showing the sand dune both at one moment and over time with data from the single-period and multi-period topography survey. This study has laid a foundation for the improvement of real-time terrain display (Tang et al. 2010).

ArcScene10 was chosen for the 3D display because of its highly-precise terrain simulations at a small scale (Mou et al. 2012). It's yet to be explored regarding the problems about the 3D modeling, the parameter settings and the selection of modeling software for large regions. This study only encompasses the generation of a terrain model and its simple terrain display. Although the model has implemented other functions, including rotation and review of the 3D model, these functions fail to add the relevant texture into the terrain model and analysis of the interactions is limited. There is much left to explore regarding the limitations with recreating a 3D terrain and understanding how it is influenced by interacting elements.

\section{Acknowledgements}

The author wants to express his appreciation for Rui Wang and Meng-Chen Chen, who was admitted to the University of Chinese Academy of Sciences in 2014. Both have participated in the surveying work of sand dune topography in the hinterlands of the Taklimakan Desert. This work was financially supported by the National Natural
Science Foundation of China (41371025) and the National Science and Technology Support Program (2015BAC06B01-01).

\section{References}

Abolkhair Y M S 1986 The statistical analysis of the sand grain size distribution of AI-Ubay-lah barchan dunes, northwestern Ar-Rub-Alkhali desert, Saudi Arabia; GeoJournal 13(2) 103-109.

Baddock M C, Livingstone I and Wiggs G F S 2007 The geomorphological significance of airflow patterns in transverse dune interdunes; Geomorphology 87 322-336.

Bo T L and Zheng X J 2011 The formation and evolution of aeolian dune fields under unidirectional wind; Geomorphology 134 408-416.

Chen S B 2005 Three-dimension visualization for texture in western slope of Songliao basin; J. Jilin Univ. 35 47-50.

Cong D G, Pang H L, Fang M, Chen X J, Liu C and Tian Y 2014 Dunes distribution study on north of Tengery desert based on remote sensing and DEM; China Min. Mag. 23 153-159.

Dinieg S, Glasner K and Byrne S 2010 Long-time evolution of models of aeolian sand dune fields: In fluence of dune formation and collision; Geomorphology 121 55-68.

Dong Z B, Qian G Q, Lu P, Luo W and Wang H 2009 Turbulence fields in the lee of two-dimensional transverse dunes simulated in a wind tunnel; Earth. Surf. Proc. Land. 34 204-216.

Du H Q, Han Z W, Deng X H, Zhang Y and Sun J H 2011 A sand flux model for the surface of barchan dunes using GIS-based spatial analysis; J. Desert. Res. 31(4) 815-823.

Durán Q, Schwämmle V, Lind P G and Herrmann H J 2009 The dune size distribution and scaling relations of barchan dune fields; Granul. Matter. 11 7-11.

Elbelrhiti H, Claudin P and Andreotti B 2005 Field evidence for surface-wave-induced instability of sand dunes; Nature 437 720-723.

Endo N, Taniguchi K and Katsuki A 2004 Observation of the whole process of interaction between barchans by flume experiments; Geophys. Res. Lett. 31(12) 5321-5329.

Faria R, Ferreira A D, Sismeiro J L, Mendes J C F and Sousa A C M 2011 Wind tunnel and computational study of the stoss slope effect on the Aeolian erosion of transverse sand dunes; Aeolian Res. 3 303-314.

Frank A and Kocurek G 1996 Airflow up the stoss slope of sand dune: Limitation of current understanding; Geomorphology 17 47-56.

Gómez-Ortiz D, Martín-Crespo T, Rodríguez I, Sánchez M J and Montoya I 2009 The internal structure of modern barchan dunes of the Ebro River Delta (Spain) from ground penetrating radar; J. Appl. Geophys. 68 159-170.

Han Z W, Du H Q, Gou Q Q and Sun J H 2012 The piecewise fitting of sand flux vertical distribution of wind-sand flow within $100 \mathrm{~cm}$ height above the barchan dune surface; Sci. Geogr. Sin. 32(7) 892-897.

Hersen P 2004 On the crescentic shape of barchan dunes; Eur. Phys. J. B 37 507-514.

Huang D Q, Dong Y X, Ha S and Ma J 2007 The Application of multi-station RTKGPS in the measurement of coastal 
dune; Acta. Scientiarum. Nat. U. Sunyatseni 46(4) 121124.

Hugenholtz C H and Wolfe S A 2005 Recent stabilization of active sand dunes on the Canadian prairie and relation to recent climate variations; Geomorphology 68 131147.

Käln H W and Adelaide C R T 1988 Formation and age of desert dunes in the lake eyre depocentres in central Australia; Geol. Rundsch. 77(3) 815-834.

Katagiri J, Matsushima T and Yamada Y 2010 Simple shear simulation of 3D irregularly-shaped particles by imagebased DEM; Granul. Matter. 12 491-497.

Katsuki A, Nishimori H, Endo N and Taniguchi K 2004 Collision dynamics of two barchan dunes simulated by a simple model; J. Phys. Soc. Jan. 74(2) 538-541.

Kocurek G and Ewing R C 2005 Aeolian dune field selforganization-implications for the formation of simple versus complex dune-field patterns; Geomorphology $\mathbf{7 2}$ 94-105.

Li H P and Chen G T 1999 Retrograde evolution of barchan on interdune corridor of complex ridges in central Taklimakan desert; J. Desert. Res. 19(2) 134-138.

Ling Y Q, Wu Z, Liu S Z and Li C Z 1998 Simulating study on barchan dune; Chinese Geogr. Sci. 8(2) 168-175.

Li S, Liu X W, Li H C, Zheng Y H and Wei X H 2007 A wind tunnel simulation of the dynamic processes involved in sand dune formation on the western coast of Hainan island; J. Geogr. Sci. 17(4) 453-468.

Li T W 2010 Modern surveying; Science Press, Beijing.

Mckee E D 1966 Structures of dunes at White Sands National Monument, New Mexico; Sedimentology 7(1) 1-69.

Moosavi V, Shamsi S R F, Moradi H and Shirmohammadi B 2014 Application of Taguchi method to satellite image fusion for object-oriented mapping of barchan dunes; Geosci. J. 18(1) 45-49.

Mou N X, Liu W B, Wang H Y and Dai H L 2012 The tutorial of ArcGIS10 geographic information system; Surveying and Mapping Publishing House, Beijing.

Palmer J A, Mejia-Alvarez R, Best J L and Christensen K T 2012 Particle-image velocimetry measurements of flow over interacting barchan dunes; Exp. Fluids $\mathbf{5 2}$ 809-829.

Parsons D R, Wiggs G F S, Walker I J, Ferguson R I and Garvey B G 2004a Numerical modeling of airflow over an idealized transverse dune; Environ. Modell. Softw. 19 $153-162$

Parsons D R, Walker I J and Wiggs G F S 2004b Numerical modeling of flow structures over idealized transverse aeolian dunes of varying geometry; Geomorphology $\mathbf{5 9}$ 149-164.

Qi R, Qi M and Li K 2014 The research on the method of 3D terrain generation based on the digital terrain map; Electron. Des. Eng. 22(7) 191-193.

Ruiz-arias J A, Tovar-pescador J, Pozo-vazquez D and Alsamamra H 2009 A comparative analysis of DEM-based models to estimate the solar radiation in mountainous terrain; Int. J. Geogr. Inf. Sci. 23(8) 1049-1076.
Samani A N, Khosravi H, Mesbahzadeh T, Azarakhshi M and Rahdari M R 2016 Determination of sand dune characteristics through geomorphometry and wind data analysis in central Iran (Kashan Erg); Arab. J. Geosci. 9 716.

Samavati F and Runions A 2016 Interactive 3D content modeling for digital earth; Vis. Comput. 32 1293-1309.

Schwämmle V and Herrmann H J 2005 A model of Barchan dunes including lateral shear stress; Eur. Phys. J. E 16 $57-65$.

Sibson R 1981 A brief description of natural neighbour interpolation. In: Interpreting Multivariate Data 21 21-36

Stam J M T 1997 On the modeling of two-dimensional aeolian dunes; Sedimentology 44 127-141.

Tsoar H and Parteli E J R 2016 Bidirectional winds, barchan dune asymmetry and formation of Seif dunes from barchans: A discussion; Environ. Earth. Sci. 75(18) 1237.

Tang G A, Li F Y and Liu X J 2010 Digital elevation mode course; Science Press, Beijing.

Tang G A and Yang X 2012 ArcGIS geographic information system spatial analysis experiment course; Science Press, Beijing.

Walker I J and Nickling W G 2003 Simulation and measurement of surface shear stress over isolated and closely spaced transverse dunes in a wind tunnel; Earth. Surf. Proc. Land. 28 1111-1124.

Wang C, Li H, Yang J S and Yang C C 2015 Study on generation technique of high quality contour lines based on grid DEM; Acta. Geol. Sinica. 17(2) 160-165.

Weng W S, Hunt J C R, Carruthers D J, Warren A, Wiggs G F S, Livingstone I and Castro I 1991 Air flow and sand transport over sand-dunes; Acta. Mech. Suppl. 2 $1-22$.

Werner B T 1995 Eolian dunes: Computer simulations and attractor interpretation; Geology 23 1107-1110.

Wiggs G F S, Livingstone I and Warren A 1996 The role of streamline curvature in sand dune dynamics: Evidence from field and wind tunnel measurements; Geomorphology $1729-46$.

Wu Z 1987 Aeolian geomorphology; Science Press, Beijing.

Xia J S and Dong P L 2016 A GIS add-in for automated measurement of sand dune migration using LiDAR-derived multitemporal and high-resolution digital elevation models; Geosphere 12(4) 1316-1322.

Xiang J S, Munjiza A, Latham J and Guises R 2009 On the validation of DEM and FEM/DEM models in $2 \mathrm{D}$ and $3 \mathrm{D}$; Eng. Comput. 26(6)673-687.

Yang N, Su L L, Wan L, Yang J, Chen S Y and Hu W L 2016 A method for building 3D models of barchan dunes; Geomorphology 253 181-188.

Yan L and Yang L H 2009 Based on Delaunay triangulation DEM of terrain model; Comput. Inf. Sci. 2(2) 137.

Zhang C L, Hao Q Z, Zou X Y and Yan P 1999 Response of morphology and deposits to surface flow on windward slope of barchan dune; J. Desert. Res. 19(4) 359-363. 